\title{
Memory $\mathrm{T}$ cells as an occupying force
}

\author{
Michael J. Bevan \\ Department of Immunology, Howard Hughes Medical Institute, University of Washington, Seattle, \\ WA, USA
}

\begin{abstract}
There is debate over whether effective T-cell mediated protection against a second infection, or post-vaccination, is better done by central memory cells or effector memory cells. The former may have greater powers of expansion, whereas the latter may be closer to the site of pathogen entry and faster to respond. This review focuses on memory $\mathrm{T}$ cells which are not recirculating but which remain at the peripheral site of initial pathogen or vaccine encounter, so-called tissueresident memory cells. They may play key roles in protection against re-eruption of latent viral infections and at mucosal surfaces.
\end{abstract}

\section{Keywords}

Cell survival; Memory cells; T cells

\begin{abstract}
After leaving the thymus, newly generated $\mathrm{T}$ cells have a few steps of continued maturation or polishing to undergo before they become fully mature naïve T cells [1]. As naïve cells, peripheral $\mathrm{T}$ cells migrate between the blood and the lymphoid structures in the spleen and lymph nodes in search of their cognate antigen. When T cells do encounter antigen on activated DCs in central lymphoid organs, they proliferate and differentiate into effector $\mathrm{T}$ cells. While some antigen-activated $\mathrm{T}$ cells, such as $\mathrm{CD} 4^{+}$follicular helper $\mathrm{T}$ cells, may remain in the central lymphoid organs to deliver help to B cells [2], those effector cells whose work is at the peripheral site of antigen entry must travel to this site via the bloodstream. Using cues from activated endothelial cells at sites of inflammation [3], T cells leave the blood vessels and enter tissues once more in search of antigen. When antigenbearing cells are killed or accessory cells are activated to degrade or contain antigen, effector cells egress from the tissues via the afferent lymphatics. In some cases, a few effector cells remain behind; these tissue-resident memory $\mathrm{T}$ cells are the subject of this review [4].
\end{abstract}

When antigen has been cleared, a contraction phase follows during which time the number of effector cells declines through apoptosis leaving behind some survivors that go on to differentiate into memory $\mathrm{T}$ cells. Central memory cells retain similar homing and chemokine receptors and routes of recirculation as naïve $\mathrm{T}$ cells, whereas effector memory $\mathrm{T}$

Full correspondence: Dr. Michael J. Bevan, Department of Immunology, Howard Hughes Medical Institute, University of Washington, Seattle, WA 98195, USA, Fax: +1-206-685-3612, mbevan@u.washington.edu.

Conflict of interest: The author declares no financial or commercial conflict of interest. This article is editorially independent of Novartis.

See accompanying reviews also written by winners of the 2010 Novartis Immunology Prizes, and the Forum article describing the Prizes 
cells no longer routinely enter lymph nodes and are more prone to enter nonlymphoid tissues [5]. At any one time, a large fraction of the total T-cell pool in a healthy individual is distributed in nonlymphoid tissues [6-8]. These lymphocytes have the phenotype of effector memory cells and most are thought to be cells in transit through tissues, on their way back to the bloodstream.

As reviewed here, it now appears that some of these peripheral memory cells, so-called tissue-resident memory $\mathrm{T}$ cells, have permanently left the circulating memory pool and have taken up residence in nonlymphoid tissues. In some cases, the rationale for this is clear: having dealt with an infection at a particular site, the T cells stay on site to quickly deal with a subsequent appearance of antigen such as would occur following the recrudescence of a latent infection. This view is most simply applied to recent findings, following skin or mucosal infection with herpes virus and the subsequent latent infection of the innervating sensory ganglia.

\section{Herpes simplex virus in sensory ganglia}

From an initial site of entry such as skin or other epithelial surfaces, HSV-1 infects local nerve endings and is carried to the innervating sensory ganglia by retrograde axonal flow where the virus can remain within neurons in various degrees of dormancy depending on the virus and the host species [9]. In mice, the virus may be retained for the lifetime of the animal in infected neurons without full recrudescence at the initial site of infection. Virusspecific $\mathrm{CD}^{+} \mathrm{T}$ cells are important in controlling the early replication of the virus both at the site of entry and in the infected ganglia. However, in addition to this acute role, HSVspecific $\mathrm{CD} 8^{+} \mathrm{T}$ cells remain in the ganglia long after viral replication ceases. Many of these resident $\mathrm{T}$ cells express markers associated with recent antigen activation such as CD69 and high levels of granzymes, and this is true even for those $\mathrm{T}$ cells specific for structural (glycoprotein) epitopes of the virus, not just for latency-associated antigens [10, 11]. How far production of viral particles goes in the mouse is debated and in this situation constant or recurrent contact with MHC/peptide antigen may be involved in keeping the virus-specific $\mathrm{T}$ cells in the ganglion. When an HSV-1-infected ganglion is surgically excised and placed in organ culture or transplanted under the kidney capsule of uninfected mice, however, virus gene expression ramps up and, in the transplantation model, the virus-specific resident memory $\mathrm{CD} 8^{+} \mathrm{T}$ cells rapidly expand. This expansion has been shown to depend on the influx of inflammatory dendritic cells serving as antigen-presenting cells in the ganglion [12]. Circulating HSV-1-specific memory T cells can also be recruited to the transplanted ganglion, but the kinetics of their response lags behind that of the resident memory cells [13].

The mouse model of HSV-1 infection provides a clear example of how tissue-resident memory $\mathrm{T}$ cells provide rapid containment of a local, latent infection. In this case, it has not been established whether the long-term residence of the T cells in the sensory ganglion is dependent on prolonged antigen exposure due to continued viral gene expression; however, when we consider the initial site of HSV-1 infection in the skin, it appears that prolonged antigen exposure is unnecessary to keep memory $\mathrm{T}$ cells on site.

\section{Skin-resident memory}

Scarification of flank skin and infection with HSV-1 is followed by viral replication in epidermal cells and latent infection of neurons in the local dorsal root ganglia. After the skin lesions heal and virus is no longer detectable, $\mathrm{CD}^{+} \mathrm{T}$ cells specific for HSV-1 remain behind in the epidermis. Subsequent ipsilateral versus contralateral flank rechallenge with virus reveals that the ipsilateral side is much more resistant to viral replication in the epidermis and this protection is T-cell mediated [14]. In this case, it is unlikely that memory 
$\mathrm{T}$ cells are retained in skin due to prolonged antigen presentation because infectious virus is not produced in the infected neurons to traffic back to the original site of infection.

Furthermore, when previously infected skin is grafted to a naïve animal and nerve endings are severed, the HSV-specific T cells remain in the graft [14]. Skin-resident CD8 ${ }^{+} \mathrm{T}$ cells, unlike memory cells in the spleen, express high levels of integrins CD103 and VLA-1. The known ligand for CD103 is E-cadherin which is expressed at high levels by the epithelial cells. Although HSV-1 does not recrudesce in mice and spread from the latently infected ganglia back to the skin, this model system provides a wonderful example of how adaptive immune memory attempts to predict the site of re-entry or reactivation of an infectious agent.

Fixed drug eruptions provide intriguing evidence from the clinic that the skin is a patchwork of fixed or sessile resident memory $\mathrm{T}$ cells. Observations in some patients show specific skin lesions at reproducible sites on their skin when administered a drug orally [15]. The lesions have been described as classic delayed-type hypersensitivity reactions with $\mathrm{CD} 8^{+} \mathrm{T}$ cells as the mediators but in which the trigger is delivered systemically and the reactive $\mathrm{T}$ cells are local. Whether the drug or its metabolites cause the reaction is not known, nor is the identity of the original insult that generates such a fixed site of local memory.

In addition to memory cells that remain for extended periods in the epidermis at sites of prior infection, a large fraction of circulating memory $\mathrm{T}$ cells expresses the adhesion molecule cutaneous lymphocyte antigen (CLA) which mediates preferential migration into and through the skin. Clark has estimated that 20 billion memory $\mathrm{T}$ cells are present in our skin, outnumbering those present in the entire circulation [6]. Such tissue-selective homing may be imprinted on the responding $\mathrm{T}$ cells in skin-draining lymph nodes. It seems reasonable that, as a major portal of exposure to the outside world, the skin is subjected to heightened immune surveillance by circulating memory $\mathrm{T}$ cells, whereas site-specific resident memory cells protect against reprisal of an old infection.

\section{Resident memory in the central nervous system}

Mice primed with influenza virus and then challenged by injection of a neurotropic strain of the virus into a cerebral ventricle showed massive recruitment of memory $\mathrm{T}$ cells into the brain which rescued the animals from fatal encephalitis [16]. Strikingly, the numbers of activated, influenza-specific $\mathrm{CD} 8^{+} \mathrm{T}$ cells within the brain remained elevated for a year in the absence of clear evidence of persisting influenza antigen. Given the known isolation of the CNS from the recirculating pool lymphocytes, this finding suggested the long-term residence of memory $\mathrm{T}$ cells at this site. In a simple but informative experiment, Klonowski et al. [17] joined the circulation of pairs of congenically marked mice by parabiosis to examine the dynamics of memory T-cell trafficking. They reported that while memory cells in most tissues and organs equilibrated with kinetics similar to the mixing of the bloodstreams, memory $\mathrm{CD} 8^{+} \mathrm{T}$ cells in the brain and intestinal mucosa of partner mice did not equilibrate. Further evidence that memory $\mathrm{CD}^{+} \mathrm{T}$ cells in the CNS are separated from the recirculating memory pools was presented by Wei et al. [18], who showed that peptide injection could not delete memory $\mathrm{T}$ cells in the brain although memory cells in all other tissues were deleted.

Intranasal infection with vesicular stomatitis virus (VSV) not only results in respiratory tract infection, but also allows the virus to spread to the brain via the olfactory nasal epithelium and its connection to the olfactory bulb [19]. Following infection via the nares, we observed "hot spots" of VSV infection throughout the brain early after infection [20]. Virus-specific $\mathrm{CD} 8^{+} \mathrm{T}$ cells flooded into the brain after being activated in peripheral lymphoid organs, swarmed around the VSV-infected hot spots and cleared the infection by 8 days. Numbers of 
$\mathrm{CD}^{+} \mathrm{T}$ cells in the brain plunged thereafter but a fraction remained in the brain for months and these resident lymphocytes were grouped into clusters in the brain parenchyma, presumably at the previous hot spots of infection. These memory $\mathrm{CD} 8^{+} \mathrm{T}$ cells did not mix with the circulation, and were unique in their high expression of CD103 and low level expression of CD122. Upregulation of CD103 was absolutely dependent on the T cells interacting with their antigen in the brain. On-site recognition of viral antigen and CD103 expression determined, to a great extent, the number of virus-specific memory cells that remained in the CNS. In these experiments, viral antigen or viral genomic RNA could not be detected in the CNS memory T-cell clusters. Interestingly, when mice were primed by intracerebral injection of peptide-loaded dendritic cells, CD103 ${ }^{+}$memory CD8 ${ }^{+} \mathrm{T}$-cell clusters were also observed at the site of injection, once again speaking against the notion that prolonged antigen persistence is a requirement for resident memory [20].

The significance of VSV-specific $\mathrm{CD}^{+} \mathrm{T}$ cells remaining sessile in clusters at (presumed) previous hot spots of infection is not obvious because VSV is not a chronic, persistent or latent viral infection. The author's interpretation is that the T cells are not "smart" enough to know this, and are simply fulfilling a protective role against an infection that might recur at the same site.

\section{T cells in the intestinal mucosa}

Gut-associated memory $\mathrm{T}$ cells are also out of equilibrium with the pool of recirculating memory cells [17]. T cells that have been recently activated by antigen in gut draining lymphoid organs such as mesenteric lymph nodes preferentially acquire homing molecules that allow them to enter the lamina propria and intestinal epithelium [21]. In addition, effector $\mathrm{T}$ cells activated in the spleen by viral or bacterial infection have the ability to traffic to any organ, including the gut [22]. Thus, it seems that recently activated effector cells can enter these sites, but resting memory cells cannot. The lymphocytes in the gutassociated lymphoid structures show an activated phenotype, including CD69 and granzyme expression and immediate effector function. The gut lumen contains a vast spectrum of microbial and food antigens which are usually ignored by the immune system. Nevertheless, the enormous surface area of the intestine and its exposure to ingested pathogens make it a key location for enhanced security. Despite the huge number of potential peptides in the gut derived from commensals and food, it is difficult to argue that all the resident memory $\mathrm{T}$ cells in the gut epithelium and underlying structures meet antigen (or cross-reactive antigen) at this location. Rather it may be that their activated status provides an antigen nonspecific or innate function in maintaining the integrity of the intestine.

\section{Concluding remarks}

Peripheral nonlymphoid organs and body surfaces, such as the skin and mucosa, contain the bulk of our lymphocytes. These are virtually all memory cells and many score as effectors. Their role is to provide a rapid response to pathogen re-entry or reactivation; however, for these $\mathrm{T}$ cells on the front lines of our defenses, it still remains to be worked out what factors hold and maintain them at these locations.

\section{Abbreviation}

VSV vesicular stomatitis virus 


\section{References}

1. Boursalian TE, Golob J, Soper DM, Cooper CJ, Fink PJ. Continued maturation of thymic emigrants in the periphery. Nat Immunol. 2004; 5:418-425. [PubMed: 14991052]

2. Fazilleau N, Mark L, McHeyzer-Williams LJ, McHeyzer-Williams MG. Follicular helper T cells: lineage and location. Immunity. 2009; 30:324-335. [PubMed: 19303387]

3. Woodland DL, Kohlmeier JE. Migration, maintenance and recall of memory T cells in peripheral tissues. Nat Rev Immunol. 2009; 9:153-161. [PubMed: 19240755]

4. Wakim LM, Bevan MJ. From the thymus to longevity in the periphery. Curr Opin Immunol. 2010; 22:274-278. [PubMed: 20378321]

5. Sallusto F, Geginat J, Lanzavecchia A. Central memory and effector memory T cell subsets: function, generation, and maintenance. Annu Rev Immunol. 2004; 22:745-763. [PubMed: 15032595]

6. Clark RA. Skin-resident T cells: the ups and downs of on site immunity. J Invest Dermatol. 2010; 130:362-370. [PubMed: 19675575]

7. Reinhardt RL, Khoruts A, Merica R, Zell T, Jenkins MK. Visualizing the generation of memory CD4 T cells in the whole body. Nature. 2001; 410:101-105. [PubMed: 11242050]

8. Masopust D, Vezys V, Marzo AL, Lefrancois L. Preferential localization of effector memory cells in nonlymphoid tissue. Science. 2001; 291:2413-2417. [PubMed: 11264538]

9. Decman V, Freeman ML, Kinchington PR, Hendricks RL. Immune control of HSV-1 latency. Viral Immunol. 2005; 18:466-473. [PubMed: 16212525]

10. Khanna KM, Bonneau RH, Kinchington PR, Hendricks RL. Herpes simplex virus-specific memory CD8+ T cells are selectively activated and retained in latently infected sensory ganglia. Immunity. 2003; 18:593-603. [PubMed: 12753737]

11. Khanna KM, Lepisto AJ, Decman V, Hendricks RL. Immune control of herpes simplex virus during latency. Curr Opin Immunol. 2004; 16:463-469. [PubMed: 15245740]

12. Wakim LM, Waithman J, van Rooijen N, Heath WR, Carbone FR. Dendritic cell-induced memory T cell activation in nonlymphoid tissues. Science. 2008; 319:198-202. [PubMed: 18187654]

13. Wakim LM, Gebhardt T, Heath WR, Carbone FR. Cutting edge: local recall responses by memory T cells newly recruited to peripheral nonlymphoid tissues. J Immunol. 2008; 181:5837-5841. [PubMed: 18941171]

14. Gebhardt T, Wakim LM, Eidsmo L, Reading PC, Health WR, Carbone FR. Memory T cells in nonlymphoid tissue that provide enhanced local immunity during infection with herpes simplex virus. Nat Immunol. 2009; 10:524-530. [PubMed: 19305395]

15. Shiohara T. Fixed drug eruption: pathogenesis and diagnostic tests. Curr Opin Allergy Clin Immunol. 2009; 9:316-321. [PubMed: 19474709]

16. Hawke S, Stevenson PG, Freeman S, Bangham CR. Long-term persistence of activated cytotoxic T lymphocytes after viral infection of the central nervous system. J Exp Med. 1998; 187:1575-1582. [PubMed: 9584136]

17. Klonowski KD, Williams KJ, Marzo AL, Blair DA, Lingenheld EG, Lefrancois L. Dynamics of blood-borne CD8 memory T cell migration in vivo. Immunity. 2004; 20:551-562. [PubMed: 15142524]

18. Wei CH, Trenney R, Sanchez-Alavez M, Marquardt K, Woodland DL, Henriken SJ, Sherman LA. Tissue-resident memory CD8+ T cells can be deleted by soluble, but not cross-presented antigen. J Immunol. 2005; 175:6615-6623. [PubMed: 16272316]

19. Reiss CS, Plakhov IV, Komatsu T. Viral replication in olfactory receptor neurons and entry into the olfactory bulb and brain. Ann NY Acad Sci. 1998; 855:751-761. [PubMed: 9929681]

20. Wakim LM, Woodward-Davis A, Bevan MJ. Memory T cells persisting within the brain after local infection show functional adaptations to their tissue of residence. Proc Natl Acad Sci USA. 2010; 107:17872-17879. [PubMed: 20923878]

21. Sigmundsdottir H, Butcher EC. Environmental cues, dendritic cells and the programming of tissueselective lymphocyte trafficking. Nat Immunol. 2008; 9:981-987. [PubMed: 18711435] 
22. Masopust D, Choo D, Vezys V, Wherry EJ, Duraiswamy J, Akondy R, Wang J, et al. Dynamic T cell migration program provides resident memory within intestinal epithelium. J Exp Med. 2010; 207:553-564. [PubMed: 20156972] 